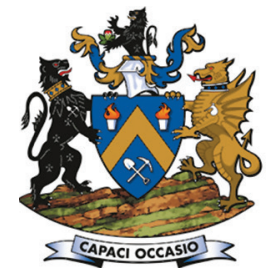

Affiliation:

${ }^{1}$ Centre of Excellence in

Carbon-based Fuels, School of Chemical and Minerals Engineering, North-West University, Potchefstroom, South Africa.

Correspondence to:

N.T. Leokaoke

Email:

nthabiseng.leokaoke@nwu.ac.za

Dates:

Received: 6 Mar. 2020

Revised: 3 Feb. 2021

Accepted: 3 Feb.2021

Published: March 2021

\section{How to cite:}

Botha, D.L., Leokaoke, N.T.

Bunt, J.R., and Neomagus,

H.W.J.P. 2021

Evaluation of polymer binders in briquetting of coal fines for combustion applications.

Journal of the Southern African Institute of Mining and Metallurgy, vol. 121, no. 3, pp. 113-118.

DOI ID:

http://dx.doi.org/10.17159/24119717/991/2021

ORCID

D.L. Botha

https://orchid.org/0000-0002-

3018-6964

J.R. Bunt

https://orchid.org/0000-0003-

3051-2528

\title{
Evaluation of polymer binders in briquetting of coal fines for combustion applications
}

\author{
D.L. Botha ${ }^{1}$, N.T. Leokaoke', J. R. Bunt ${ }^{1}$, and H.W.J.P. Neomagus ${ }^{1}$
}

\begin{abstract}
Synopsis
Coal briquetting traditionally makes use of high-dosage, nonpolymeric binders (such as coal tar pitch or molasses) or polyvinyl alcohol (PVA) at low dosages for the binding of fine and ultrafine coal. Due to constraints associated with the manufacturing and cost of PVA-bound briquettes, a novel polyacrylic binder was developed that could possibly be added in low dosages at room temperature. A set of formulations of two polyacrylic components (components A and B) was developed, from which an optimal binder mixture was determined. This formulation comprises $40 \mathrm{wt} . \%$ component A and $10 \mathrm{wt} . \%$ component B with a $0.04 \mathrm{wt} . \%$ cross-linking additive, and the balance water. The uniaxial briquette compressive strength was used to obtain the optimal binder mixture. The binder mixture was added to the coal powder in dosages from 0.1 to $1.2 \mathrm{wt} . \%$. Mechanical tests and thermogravimetric analysis in an oxidized environment at a maximum temperature of $930^{\circ} \mathrm{C}$ were conducted. Binder-bound briquettes were compared to binderless briquettes and PVA-bound briquettes. Briquettes made from the polyacrylic formulation had uniaxial compressive strengths double that of the binderless briquette yield strength, as well as the minimum recommended compressive strength of $0.375 \mathrm{MPa}$. The organic binders did not affect the combustion of the briquettes, since the results compared well with the binderless briquettes. The polyacrylic formulation is considered to be a possible substitute for PVA in terms of mechanical and thermal properties and raw material cost.
\end{abstract}

\section{Keywords}

briquettes, fine coal, polymer binders, polyvinyl alcohol, combustion.

\section{Introduction}

Coal is still a major energy resource for electricity generation worldwide. Coal usage is holding steady and not rapidly decreasing, despite the planned implementation of national policies in several parts of the world to reduce consumption. This is because of spatial and market-related factors, including accessibility, supply, and demand (Song and Wang, 2019). The coal mining industry has improved its safety and efficiency record through mechanization; however, this has led to an increase in fines generation (particles with a $1 \mathrm{~mm}$ top size) (Vogt, 2016). Fines constitute 6-12\% of run-of-mine coal and have accumulated in vast amounts over the past one-and-a-half centuries (Reddick, von Blottnitz, and Kothuis, 2007; Venter and Naude, 2015). For this reason, fines reclamation initiatives have been initiated both locally and globally (Garling, 2015; Senkhane, 2018).

The reclaimed fines are moist and difficult to transport, and cause pollution where they are stored and transported (CATF, 2001; England, 2013; Karmakar, 2005). The cost of drying fine and ultrafine coal can reduce its value as a fuel source because mechanical dewatering is unfeasible, thermal drying is unsafe, filtration techniques are ineffective, and other techniques may become time-consuming and expensive as higher amounts of sorption additives are needed for smaller particle sizes (Reddick von Blottnitz, and Kothuis, 2007; van Rensburg et al., 2018). Agglomeration is a possible process to alleviate the problems associated with low-value coal fines by creating a compacted product that is easier to handle and transport (England, 2013; Karmakar, 2005). Briquetting is a preferred form of agglomeration and the binderless briquetting of some South-African coals has been attempted in various studies, sometimes as a control group for testing additives or binders (de Korte, 2010; Mangena et al., 2004; Mangena and du Cann, 2007; Motaung et al., 2007; Venter and Naude, 2015). This form of briquetting is more often applicable when the coal fines have a high vitrinite content as well as an appropriate free moisture content, aiding in the briquetting process (England, 2013; Mangena et al., 2004). For agglomeration of low-vitrinite coals, binders are used when the inherent coal properties inhibit binderless briquetting (England, 2013; Klima, Arnold, and Bethell, 2012).

The great disadvantage of binders is that they constitute up to $60 \%$ of the briquetting costs (Venter and Naude, 2015). Nonpolymeric binders achieve the highest yield strengths at additions above 5wt.\%, 


\section{Evaluation of polymer binders in briquetting of coal fines for combustion applications}

and this high addition has been overcome by using the polymer alternative, polyvinyl alcohol (PVA), which is effective in lower dosages between 0.1 and 0.9wt.\% (Henning et al., 2018; Modiri, 2016; Venter and Naude, 2015). However, polyvinyl alcohol is difficult to manufacture from the raw powder form and may have higher energy requirements due to its aqueous solution temperature of above $90^{\circ} \mathrm{C}$ (Xu et al., 2018). To overcome this constraint a polyacrylic binder was recently developed, that can be manufactured at room temperature (Michailovski et al., 2018). The binder consists of two crosslinked polymer components (component $\mathrm{A}$ and component $\mathrm{B}$ ) that can be used as a binder at low concentrations, ranging between 0.1 and $1.2 \mathrm{wt} . \%$ (Michailovski., 2018). The aim of this study was to evaluate coal briquettes made using the polyacrylic binder in terms of mechanical and combustion performance in comparison to PVAbound briquettes.

\section{Experimental}

The coal used in this study originated from the Witbank coalfield. Two samples were obtained at different intervals for comparison purposes and the same coalfield was used to ensure that the coals were a true reflection of what would be used as feed material at any given instance. Both coals were of medium rank C. Table I summarizes the characteristics of the two bituminous coals.

From Table I it can be seen that the greatest difference between the two coals is their inherent moisture $(2.1 \%$ variation), ash yield (6.8\% variation), and elemental oxygen content (5.3\% variation). These results could indicate that coal 2 was more exposed to arid conditions, resulting in increased oxidation and dryness. The increased ash yield could be due to the uneven distribution of pyritic particles in the coal bed from which the coals were sampled, leading to both a higher ash yield and a higher elemental oxygen content.

\section{Binder preparation}

Components A and B were obtained in a semi-hydrated paste form at $99.9 \%$ purity, along with a crosslinking additive, and demineralized water from the Mooirivier reservoir. An antifoaming agent was added to the water prior to formulating the binder, to avoid the formation of non-homogenized mixtures. The two polymer-based components of the polyacrylic binder (PA) were each hydrated to $50 \mathrm{wt} . \%$ and mixed in liquid form using an overhead stirrer for 10 minutes in ratios between 25 and $40 w t \%$. From $0.04-1 w t \%$ crosslinking agent was then added. The solution was mixed for another 10 minutes. The polyvinyl alcohol was obtained as a powder at $99.0 \%$ purity, which was dissolved using the same demineralized water to form a colloidal solution of $0.05 \mathrm{wt} . \%$. The mixture was magnetically stirred on a hotplate stirrer for 10 minutes at $95^{\circ} \mathrm{C}$ until solubilized. The solution was then left to cool at ambient conditions and bottled for storage. The polyacrylic solution could not be stored as the effective life of the solution was unknown, and new batches were manufactured every 15 minutes.

\section{Briquette manufacture}

A Komarek B050 briquetting press was used at a feed screw speed of $80 \mathrm{r} / \mathrm{min}$, a roll speed of $3.8 \mathrm{r} / \mathrm{min}$, a gap width of $0.3 \mathrm{~mm}$, and a resulting roll compaction force of $30 \mathrm{kN}$. The resulting pillow-shaped briquettes had a length of approximately $40 \mathrm{~mm}$, a thickness of $12 \mathrm{~mm}$, and a width of $15 \mathrm{~mm}$. The briquettes are shown in Figure 1.

The briquettes were cured in a climate-controlled room at $40 \%$ relative humidity and $22^{\circ} \mathrm{C}$. The curing process had a maximum duration of 21 days, and the briquettes were tested on days $0,1,2,7,14$, and 21 .

\section{Mechanical strength tests}

The mechanical properties of the briquettes were investigated to determine the binder formulation that yielded the highest mechanical strength in terms of uniaxial compressive strength. A comparison was drawn between binderless, polyacrylic-, and polyvinyl alcohol-bound briquettes (compared to lump coal) based on mechanical strength and combustion performance. The briquettes were tested using a Chatillon DF II series force gauge with a $12 \mathrm{~mm}$ diameter. The force was determined as the value at which the briquette broke, the recommended value being 0.35 MPa (Richards, 1990). The compressive strength was calculated using the expression:

$$
P(\mathrm{MPa})=\frac{F(N)}{A\left(m^{2}\right)} \times 10^{-6}
$$

where $P$ denotes pressure, $F$ the uniaxial compressive force, and $A$ the contact surface area (a disk shape of $1.2 \mathrm{~cm}$ diameter) of the force gauge measuring area. An average of five tests was conducted for each binder formulation. The water resistance was tested by immersing the briquettes in water for 30 minutes where possible, after which finger pressure was applied. The briquettes that maintained their original integrity were evaluated in terms of uniaxial compressive strength, and this was taken as the wet compressive strength of the briquettes (Modiri, 2016). The abrasion resistance of the briquettes was measured by tumbling in a scaled-down model of the tumbler used in a previous study (Richards, 1990), using a variable speed motor at $80 \mathrm{r} / \mathrm{min}$ for 197 revolutions. To ensure that the scaled-down model was similar in terms of the mass to volume ratio, three briquettes were tumbled (measured to weigh in the order of $17 \mathrm{~g}$ ). The fines generation was measured by sieving and weighing all particulates
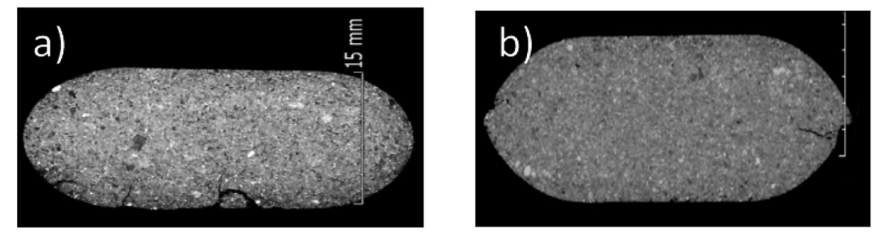

Figure 1-Briquettes manufactured using a Komarek B050 press. (a) Front view, (b) side view

\section{Table I}

Proximate, ultimate, and gross calorific value results for the two coals, wt. \%

\begin{tabular}{|c|c|c|c|c|c|c|c|c|c|c|}
\hline & $\mathrm{H}_{2} \mathrm{O}$ (ad.) & Ash yield (dry) & Vol (daf) & FC (daf) & GCV (MJ/kg) & C & $\mathbf{H}$ & $\mathrm{N}$ daf & 0 & s \\
\hline Coal 1 & 6.2 & 22.1 & 33.0 & 67.0 & 22.5 & 83.2 & 4.0 & 2.1 & 9.6 & 1.1 \\
\hline Coal 2 & 4.1 & 28.9 & 32.0 & 68.0 & 20.6 & 77.8 & 4.3 & 1.9 & 14.9 & 1.0 \\
\hline$\Delta(\%)$ & $34 \%$ & $24 \%$ & $3 \%$ & $1 \%$ & $8 \%$ & $6 \%$ & $7 \%$ & $7 \%$ & $36 \%$ & $6 \%$ \\
\hline
\end{tabular}




\section{Evaluation of polymer binders in briquetting of coal fines for combustion applications}

below $6 \mathrm{~mm}$ and taking this as a percentage of the initial sample weight. The recommended value is $5 \mathrm{wt} \%$. (Richards, 1990). The tumbler used is shown in Figure 2.

\section{Thermogravimetric analysis}

The in-house thermogravimetric analyser (TGA) described by Modiri (2016), was used to perform the combustion experiments. The set-up can be seen in Figure 3 and consists of an Afrox gas cylinder supplying dry air ( $99.8 \%$ purity) to a Sierra flow control unit. The air entered the top of a vertical Elite Thermal Systems furnace (supplied by Lenton) at a flow rate of 3 standard litres per minute (SLM). The briquettes were inserted into a quartz sample holder, which was placed on a Radwag precision PS $750 / \mathrm{C} / 2$ mass balance. The furnace was lowered over the sample holder, placing the briquettes in a pre-determined reaction zone, and temperature was measured using a K-type thermocouple. The briquettes were heated to $900^{\circ} \mathrm{C}$ while recording both mass loss and temperature with time.

To determine the optimum heating rate, binderless briquettes were heated at 3,5 , and $7^{\circ} \mathrm{C} / \mathrm{min}$ as shown in Figure 4 . The final conditions used for the thermogravimetric analysis were as follows: the coal samples were heated in dry air at a rate of 3 SLM at ambient pressure to a temperature of $900^{\circ} \mathrm{C}$, using a heating rate of $3^{\circ} \mathrm{C} / \mathrm{min}$. The briquettes were combusted non-isothermally to determine the drying zone temperature range, ignition point, maximum combustion rate, and burnout temperature. This was done for the binderless, the strongest polyacrylic binder-based, and the polyvinyl alcohol-bound briquettes.

\section{Results and discussion}

The compressive strength of all the briquettes met or exceeded the 0.35 MPa value proposed by Richards (1990) (Figure 5). The binder-bound briquettes were at least twice as strong as the binderless briquettes. The polyacrylic-bound briquettes reached a maximum compression strength of $0.9 \mathrm{MPa}$ on the second day of

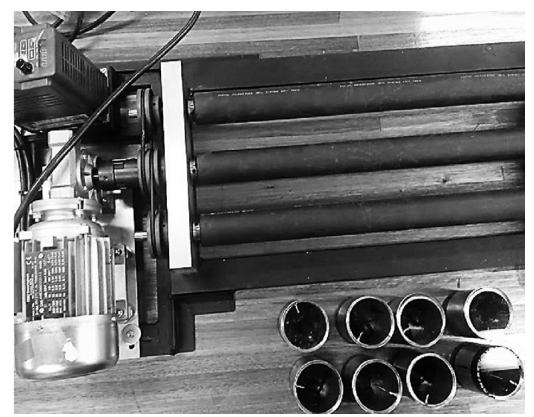

Figure 2-Scaled-down model of the tumbler test (Richards, 1990)

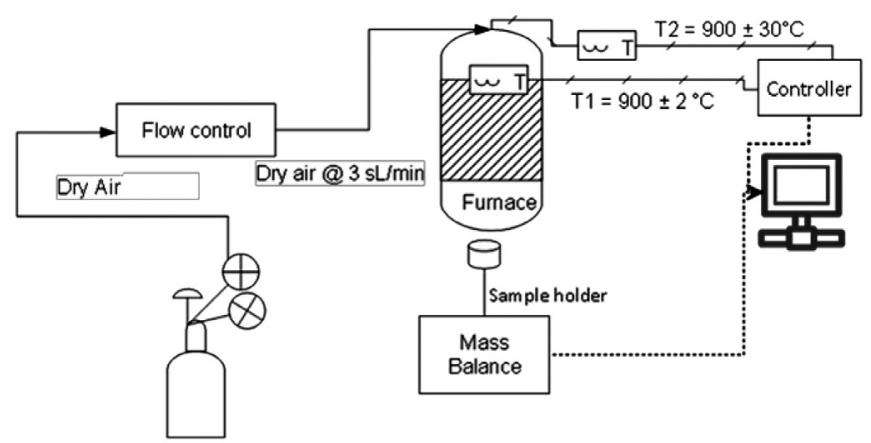

Figure 3-Thermogravimetric analyser set-up for large particles ambient curing, whereas the polyvinyl alcohol-based briquettes reached a maximum compressive strength of $0.7 \mathrm{MPa}$ on the seventh day of ambient curing. The binderless briquettes were found to reach a compressive strength plateau after the first day of curing, indicative of free moisture loss. This indicates that after the 0.9 MPa point there would be no further increase in strength. The polyacrylic- and polyvinyl alcohol-bound briquettes reached a compressive strength plateau from the seventh day of ambient curing. This indicates that a drying effect occurs on day one and a consolidation effect becomes significant until it reaches equilibrium on day 7 , depending on the environmental conditions. After the briquettes reached and exceeded the $0.35 \mathrm{MPa}$ value they were compared to lump coal pieces $(+6 \mathrm{~mm})$ as it was understood that synthetically consolidated fines could not compare in strength to natural lump coal. The shape of the lump pieces was altered by filing so that they would resemble, to the greatest possible extent, the coal briquettes. This brought about physical constraints in measuring, and therefore smaller flat pieces (still $+6 \mathrm{~mm}$ ) were broken in order to obtain a more accurate comparison. It was found that the manufactured briquettes were weaker, as the lump coal pieces had an average compressive strength of $4.2 \pm 0.3 \mathrm{MPa}$. This is approximately ten times the compressive strength of the binderless briquette and four times the maximum for both types of binder-bound briquettes. Figure 5 compares the strengths of the binder-bound and binderless briquettes.

The strongest polyacrylic binder formulation was identified as a 4:1 ratio of components $A$ to $B$. The resulting briquettes were measured against briquettes obtained from the concentration of PVA as commercially sold (0.05 wt.\% hydrated and solubilized). The effect of percentage of polymer binder addition to the coal fines was investigated and the results are shown in Figure 6.

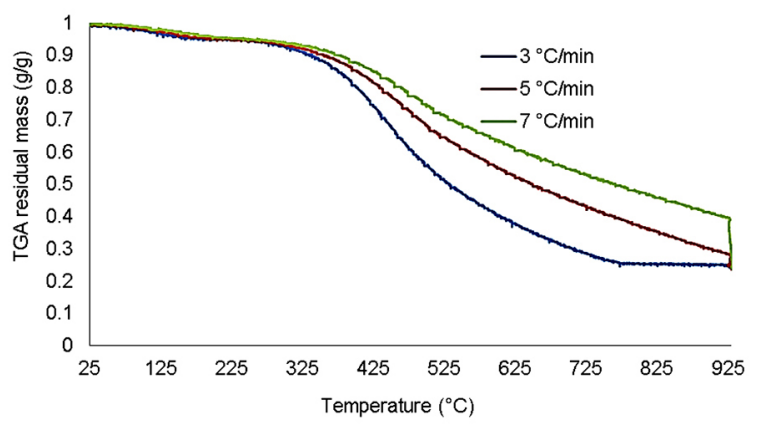

Figure 4-Comparison of the heating rates during the thermogravimetric analysis of a binderless briquette

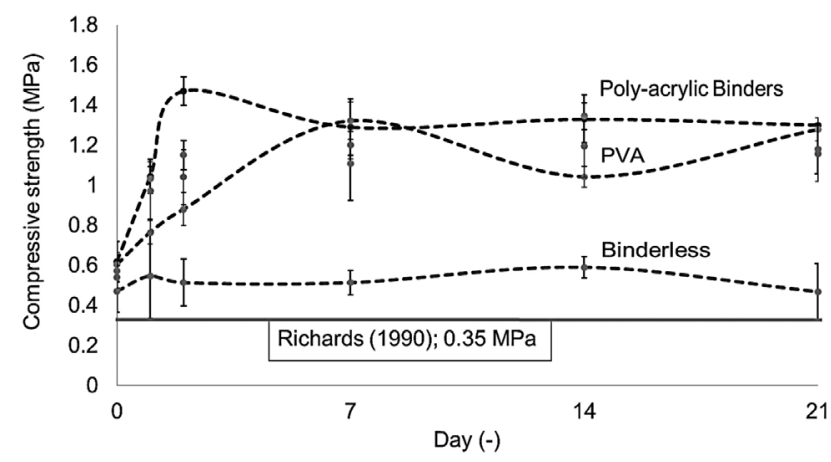

Figure 5-Compressive strength of the binderless and binder-bound briquettes over 21 days of ambient curing 


\section{Evaluation of polymer binders in briquetting of coal fines for combustion applications}

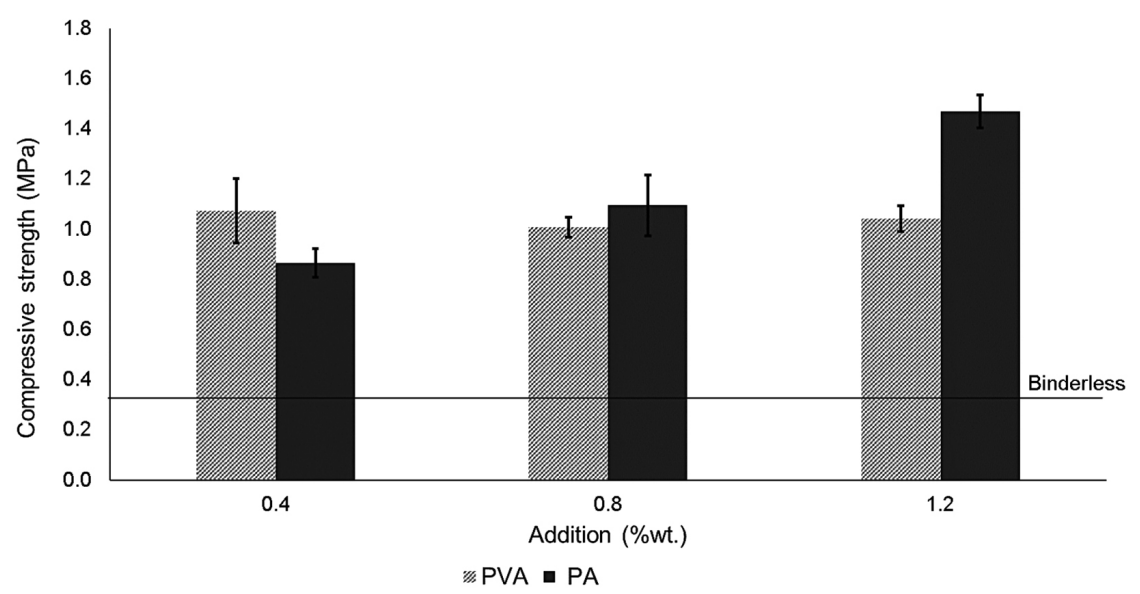

Figure 6-Compressive strength comparison between PA and PVA bound briquettes over an addition range of 0.4-1.2wt.\%

It was found that the polyvinyl alcohol briquettes had similar compressive strengths over a dosage range of $0.4-1.2 \mathrm{wt} . \%(1.1 \pm$ $0.2 \mathrm{MPa}$ ). The polyacrylic briquettes increased in strength by $0.4 \mathrm{MPa}$ as the binder addition increased from $0.4-1.2 \mathrm{wt} \%$. The PA-bound briquettes yielded a maximum compressive strength 0.2 MPa greater than that of the briquettes containing PVA.

The abrasion resistance showed similar trends to the compressive strength, except for an anomaly in the briquette with 0.8 wt. \% addition, which was found to be much less abrasion resistant. The results are shown in Figure 7.

The polyacrylic briquettes became more abrasion resistant as the binder addition was increased, with a maximum fines generation of $5 \mathrm{wt} . \%$. The polyvinyl alcohol binder-bound briquettes showed similar abrasion resistance at 0.4 and $1.2 \mathrm{wt} . \%$ additions, which was below the recommended fines generation of $5 \%$, except at $0.8 \mathrm{wt} . \%$ binder addition where the maximum fines generation was $6 \mathrm{wt} . \%$. The polyacrylic briquettes reached fines generation values below the recommended value through the entire addition range of $0.4-1.2 \mathrm{wt} . \%$.

In the water resistance tests it was found that neither the binderless nor binder-bound briquettes were water resistant across the $0.4-1.2 \mathrm{wt} . \%$ binder addition range. When the addition of the polyacrylic binder was increased to $5 \mathrm{wt} . \%$, the briquette yielded a wet compressive strength of $0.32 \mathrm{MPa}$, which is below the recommended value proposed by Richards (1990). This was the only instance where the briquettes were able to withstand the water test for a maximum of 1 minute. The dry compressive strength resulting from the $5 \mathrm{wt} . \%$ addition briquette was twice that of the $1.2 \mathrm{wt} . \%$ addition and four times the strength of the binderless briquette. The binder-bound briquettes were much weaker than the lump coal, which reached a maximum compressive strength of $6 \mathrm{MPa}$.

A comparison of the mass loss with temperature for briquettes with various mixtures of PA and PVA, as well as the raw binder components, was drawn from various runs at $5^{\circ} \mathrm{C} /$ $\min$. While the $5^{\circ} \mathrm{C} / \mathrm{min}$ heating rate was sufficient to burn out the powdered PVA and hydrated components A and B of the PA, there was a mass transfer limitation for the large briquettes, which required a lower heating rate to achieve burnout. The thermogravimetric analysis at $5^{\circ} \mathrm{C} / \mathrm{min}$ showed that the polyvinyl alcohol powder ignited at $280^{\circ} \mathrm{C}$ and the components for the polyacrylic binder at $300^{\circ} \mathrm{C}$. No significant difference was found between the binder-bound and binderless briquettes. To further evaluate the mass transfer limitation, the two heating rates were compared for identical binderless briquettes. The results are shown in Figure 8.

The briquette heated at a $3^{\circ} \mathrm{C} / \mathrm{min}$ had an ignition point at $354^{\circ} \mathrm{C}$, which was $15^{\circ} \mathrm{C}$ lower than the briquette heated at $5^{\circ} \mathrm{C} / \mathrm{min}$, which led to a burnout point within the $900-930^{\circ} \mathrm{C}$ burnout range for the powdered coal (Venter and Naude, 2015). The thermogravimetric results at a heating rate of $3^{\circ} \mathrm{C} / \mathrm{min}$ displayed no significant difference between the various zones of combustion of the briquettes. These results are summarized in Table II.

Venter and Naude (2015) obtained similar results where the PVA powder started decomposing around $225^{\circ} \mathrm{C}$ and the coal (also South African bituminous coal) started combusting around $400^{\circ} \mathrm{C}$ (Hu et al., 2018; Jinsheng, 2009). In this study it was also found that the burning characteristics of powdered coal were similar to that of the PVA-bound briquettes. When the briquettes were first charred, the ignition point was found to be around $400^{\circ} \mathrm{C}$. The ignition point of the coal and the volatile matter contained in the coal are indirectly proportional to each other. Therefore, an uncharred coal will ignite sooner (at a lower temperature) than a charred coal due to the loss of volatiles in a charred coal sample. Despite the difficulties associated with combusting coal as is, it was important to see the evolution of the volatiles (therefore the binder) as the briquettes combust directly.

In summary, the TGA evolution curves for the binderless and binder-bound briquettes showed no significant difference in the combustion performance of the briquettes. These results are shown in Figure 9.

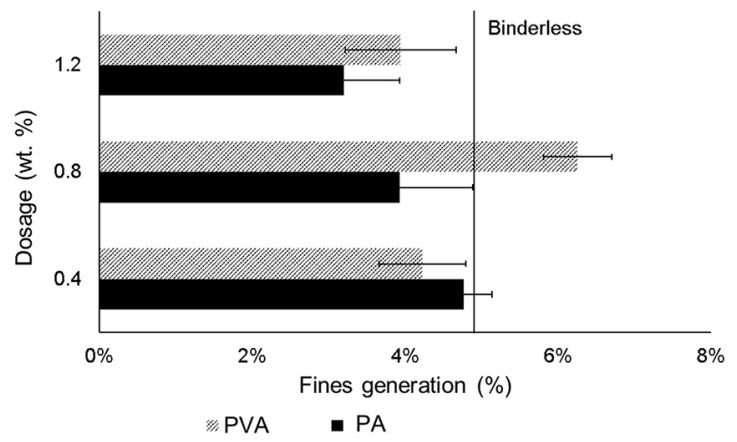

Figure 7-Comparison of abrasion resistance in terms of fines generation for PA- and PVA-bound briquettes 


\section{Evaluation of polymer binders in briquetting of coal fines for combustion applications}

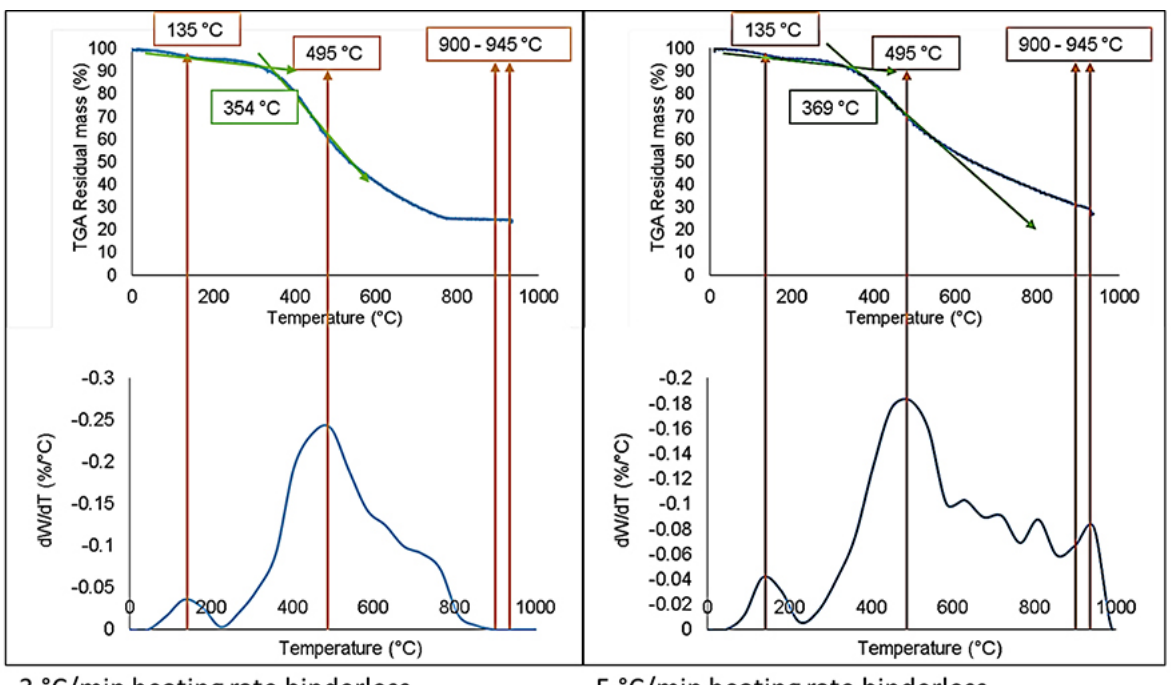

$3{ }^{\circ} \mathrm{C} / \mathrm{min}$ heating rate binderless

$5^{\circ} \mathrm{C} / \mathrm{min}$ heating rate binderless

Figure 8-Comparison on the evolution of the combustion of identical binderless briquettes with heating rates of (a) $3^{\circ} \mathrm{C} / \mathrm{min}$ and (b) $5^{\circ} \mathrm{C} / \mathrm{min}$ in dry air

Table II

Combustion zones of the binderless and binder-bound briquettes

\begin{tabular}{|c|c|c|c|c|c|c|}
\hline \multirow{2}{*}{$\begin{array}{l}3^{\circ} \mathrm{c} / \mathrm{min} \\
\text { Temperature and mean }\end{array}$} & \multicolumn{2}{|c|}{ Binderless } & \multicolumn{2}{|c|}{ PA } & \multicolumn{2}{|c|}{ PVA } \\
\hline & ${ }^{\circ} \mathrm{C}$ & \pm & ${ }^{\circ} \mathrm{C}$ & \pm & ${ }^{*} \mathrm{C}$ & \pm \\
\hline $\begin{array}{l}\text { Td: drying zone maximum } \\
\text { Tig: ignition point } \\
\text { Tm: maximum burning rate temperature } \\
\text { Tf: final burnout temperature }\end{array}$ & $\begin{array}{l}135 \\
354 \\
495 \\
855\end{array}$ & $\begin{array}{l}0 \\
3 \\
0 \\
0\end{array}$ & $\begin{array}{l}135 \\
352 \\
450 \\
855\end{array}$ & $\begin{array}{l}0 \\
3 \\
0 \\
0\end{array}$ & $\begin{array}{l}135 \\
343 \\
450 \\
855\end{array}$ & $\begin{array}{l}0 \\
1 \\
0 \\
0\end{array}$ \\
\hline
\end{tabular}

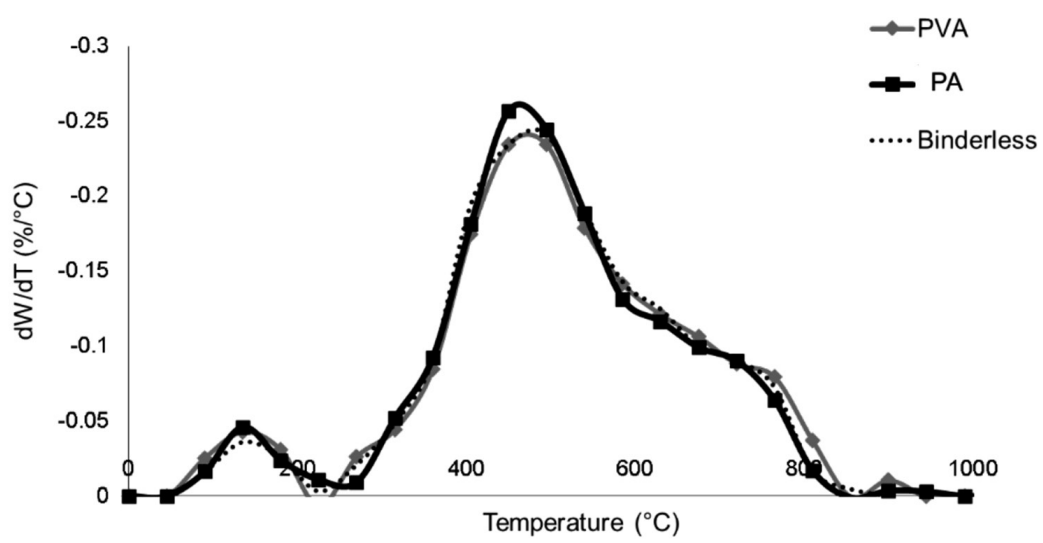

Figure 9-Evolution curve comparison of the average performance of a binderless, PA-bound, and PVA-bound briquette at $3^{\circ} \mathrm{C} / \mathrm{min}$ under dry air

The only observable difference in the evolution of the briquettes (as also presented in Table II) is that the PVA-bound briquettes ignite slightly sooner than the PA-bound briquettes. This indicates the nature of pure PVA, which reached ignition sooner than the PA binder components, and is therefore believed to decompose and release volatiles faster than PA. This difference, however, is so minor that the maximum rate for both PA- and PVA-bound briquettes is still reached at the same level of $450^{\circ} \mathrm{C}$. The binderless briquettes reach a maximum burning rate $40^{\circ} \mathrm{C}$ later, which shows a small increase in combustibility of the briquette when either PA or PVA is added.

Due to the similarity in the mechanical durability and reactivity of the PVA and PA briquettes, a simplistic cost analysis
Table III

Cost (R per ton) comparison between PVA and PA as low-dosage binders

\begin{tabular}{|l|c|c|}
\hline Binder addition (wt.\%) & PVA & PA \\
\hline 0.1 & 20 & 16 \\
0.4 & 80 & 64 \\
0.5 & 100 & 80 \\
0.9 & 178 & 142 \\
\hline
\end{tabular}

between the two binders was drawn and is shown in Table III. The cost of adding the binder at a slightly higher dosage $(0.5 \mathrm{wt} . \%$.) would be the same as for $0.4 \mathrm{wt} . \%$. polyvinyl alcohol. 


\section{Evaluation of polymer binders in briquetting of coal fines for combustion applications}

The polyacrylic binder, at the formulation that was found to be the strongest (component A to B ratio of 4:1), was found to be less expensive than polyvinyl alcohol in the addition range between 0.4 and $0.5 w t . \%$ and $0.5-0.9 w t . \%$, being equally useful and expensive at $0.5 \mathrm{wt} \%$., for the following reasons:

> The polyacrylic binder can be manufactured at room temperature, whereas polyvinyl alcohol required heating to solubilize

- The cost per ton of the polyacrylic binder is lower than that for polyvinyl alcohol.

\section{Conclusions}

Briquettes containing PA and PVA were twice as strong as binderless briquettes. Polyacrylic-bound briquettes had compressive strengths comparable to PVA-bound briquettes in the range investigated. Briquettes manufactured with the polyacrylic binders had comparable abrasion resistance to PVAbound briquettes. Briquettes should be stored in dry conditions if not waterproofed, since none of the binders offered any waterproofing abilities. The combustion performances were the same for binderless and binder-bound briquette in the range tested. The polyacrylic binder may offer an alternative to PVA since both yielded the same mechanical and reactivity analysis results, with the benefit of room temperature manufacturing.

It is recommended that methods of waterproofing the briquettes be investigated. This can be done by finding an additional component to add to the polymer constituents of the binder. Layering methods, such as wax dipping, could also be evaluated. It is also recommended that both polymer binders be tested in terms of their emissions potential, since the briquettes are to be used for combustion processes.

\section{Acknowledgements}

The work presented in this paper is based on research supported by the South African Research Chairs Initiative of the Department of Science and Innovation and National Research Foundation of South Africa (Coal Research Chair Grant No. 86880). Any opinion, finding, or conclusion or recommendation expressed in this material is that of the author(s) and the NRF does not accept any liability in this regard. Thank you to BASF for funding the project and the staff, Mr Willy Cilengi, Ms Julie Mortimer, Ms Datrium Mhlanga, Ms Ncebakazi Majeke, Ms Kagiso Tshenye, and Mr Elie Mitshiabo for the warm-hearted welcome at your facility.

\section{References}

CATF. 2001. Cradle to Grave: The environmental impacts from coal. Clean Air Task Force, Boston, MA.

DE KorTE, G. 2010. Coal preparation research in South Africa. Journal of the Southern African Institute of Mining and Metallurgy, vol. 110. pp. 361-364.

EngLAnd, T. 2013. The economic agglomeration of fine coal for industrial and commercial use. Coaltech 2020. Coaltech Research Association, Johannesburg. https://coaltech.co.za/wp-content/uploads/2019/10/Project-4.4.1-a-CoalAgglomeration-Review-of-past-and-present-work-both-locally-andinternationally-2000.pdf

GARLING, R. 2015. Tailings - a wasted resource. . TRADD Pty Ltd, Brisbane, Queensland.

Henning, C., Leokaoke, N., Bunt, J., and WaAnders, F. 2018. Testing of briquettes made from Witbank coal fines with polyvinyl alcohol as binder. Proceedings of the 10th International Conference on Advances in Science, Engineering, Technology \& Healthcare, Cape Town, South Africa, 19-20 November 2018. Eminent Association of Researchers in Engineering \& Technology. pp. 78-81.

Hu, Y., Wang, Z., Cheng, X., and MA, C. 2018. Non-isothermal TGA study on the combustion reaction kinetics and mechanism of low-rank coal char. RSC Advances, vol. 8. pp. 22909-22916.

Jinsheng, G. 2009. Coal, Oil Shale, Natural Bitumen, Heavy Oil and Peat. Vol. I. EOLSS Publications, UNESCO-EOLSS Joint Committee Secretariat, Paris, France.

Karmakar, N. 2005. Mineral Processing Technology Mpt-2005. Proceedings of the International Seminar for Material Processing Technology, 2005. McGraw Hill. pp. 275-276.

Klima, M.S., Arnold, B.J., and Bethell, P.J. 2012. Challenges in fine coal processing, dewatering, and disposal. SME, Littleton, CO.

MangenaA, S.J., De Korte, G.J., McCrindle, R.I., and Morgan, D.L. 2004. The amenability of some Witbank bituminous ultra fine coals to binderless briquetting. Fuel Processing Technology. pp.1647-1662.

Mangena, S.J. and Du Cann, V.M. 2007. Binderless briquetting of some selected South African prime coking, blend coking and weathered bituminous coals and the effect coal properties on binderless briquetting. International Journal of Coal Geology. pp. 303-312.

MichailovskiIl, A., Cilengi, W., Mortimer, J., and Bisaka, K.B. 2018. Coal binder composition. US patent application 15/576,294. BASF SE.

Modiri, N.T. 2016. An evaluation of coal briquettes using various binders for application in fixed-bed gasification. MEng thesis, North-West University, Potchefstroom, South Africa. https://repository.nwu.ac.za/bitstream/ handle/10394/25531/Modiri_NT_2016.pdf?sequence=1\&isAllowed=y

Motaung, S., Mangena, S., De Korte, G., McCrindle, R., and Van HeerdenN, J. 2007. Effects of coal composition and flotation reagents on the water resistance of binderless briquettes. Coal Preparation, vol. 27. pp. 230-248.

Reddick, J., Von Blottnitz, H., and Koтнius, B. 2007. A cleaner production assessment of the ultra-fine coal waste generated in South Africa. International Journal of Coal Preparation and Utilization, vol. 4. pp. 224-236.

Richards, S. 1990. Physical testing of fuel briquettes. Fuel Processing Technology, vol. 25. pp. $89-100$.

Senkhane, M. 2018. Forging long-term relationships that work. Inside Mining, vol. 11. pp. $14-15$.

Song, Y. and WANG, N. 2019. Exploring temporal and spatial evolution of global coal supply-demand and flow structure. Energy, vol. 168. pp. 1073-1080.

Van Rensburg, M., Le Roux, M., Campbell, Q., and Peters, E. 2018. Moisture transport during contact sorption drying of coal fines. International Journal of Coal Preparation and Utilization, vol. 40, no. 4-5. pp. 281-296.

Venter, P. and NAude, N. 2015. Evaluation of some optimum binder conditions for coal fines briquetting. Journal of the Southern African Institute for Mining and Metallurgy, vol. 115. pp. 329-333.

VoGT, D. 2016. A review of rock cutting for underground mining: Past, present, and future. Journal of the Southern African Institute of Mining and Metallurgy, vol. 116. pp. 1011-1026.

Xu, F., Zhang, H., Jin, L., Li, Y., Li, J., Gan, G., Wei, M., Li, M., and Liao, Y. 2018. Controllably degradable transient electronic antennas based on water-soluble $\mathrm{PVA} / \mathrm{TiO}_{2}$ films. Journal of Materials Science, vol. 53. pp. 2638-2647. 